Check for updates

Cite this: J. Mater. Chem. C, 2018, 6,6471

\section{Long-range ordered vertical III-nitride nano- cylinder arrays via plasma-assisted atomic layer deposition $\dagger$}

\author{
Ali Haider, (D) $\ddagger^{a}$ Petro Deminskyi, $\ddagger^{\mathrm{a}}$ Mehmet Yilmaz, ${ }^{a}$ Kholoud Elmabruk, \\ Ibrahim Yilmaz ${ }^{d}$ and Necmi Biyikli*c
}

\begin{abstract}
In this work, we demonstrate vertical GaN, AIN, and InN hollow nano-cylindrical arrays (HNCs) grown on $\mathrm{Si}$ substrates using anodized aluminum oxide (AAO) membrane templated low-temperature plasma-assisted atomic layer deposition (PA-ALD). III-Nitride HNCs have been characterized for their structural, chemical, surface, and optical properties. The material properties of nanostructured III-nitride materials have been compared with the thin-film counterparts which were also grown using PA-ALD. Our results revealed that long-range ordered arrays of III nitride HNCs were successfully integrated on Si substrates and possess hexagonal polycrystalline wurtzite crystalline structure. Such long-range ordered wafer-scale III-nitride nanostructures might be potentially used in piezotronic sensing, energy harvesting, resistive memory, flexible and wearable electronics, III-nitride photovoltaics, and (photo)catalysis.
\end{abstract}

Received 9th March 2018, Accepted 18th May 2018

DOI: $10.1039 / c 8 t c 01165 f$

rsc.li/materials-c etching to obtain various kinds of free-standing nanostructures. On the other hand, template-free or direct nanostructure fabrication methods can be mainly categorized as catalystassisted and catalyst-free techniques. Catalyst-assisted nanofabrication is achieved via high-temperature vapor liquid solid (VLS) growth where nanostructures are grown along a supersaturated catalytic liquid metal such as $\mathrm{Ni}$ or $\mathrm{Au} .{ }^{18}$ Catalyst-free methods generally utilize selective area growth of preferential growing crystallographic planes over non-preferential planes by altering the processing conditions in order to favor onedimensional material growth. ${ }^{21}$

GaN nanostructures have been prepared in variety of forms including nanorods, ${ }^{22-24}$ nanowires, ${ }^{25-35}$ and nanopillars. ${ }^{36-40}$ The common material growth methods utilized for preparing these nanostructures are arc discharge, laser ablation, metal organic chemical vapor deposition (MOCVD), and pyrolysis. ${ }^{22-40}$ Strong cathode-luminscence and/or photoluminescence from GaN nanopillars has been observed as compared to single crystalline GaN thin films, which is attributed to the high crystal quality, strain/ stress reduction, and improved anti reflection properties of $\mathrm{GaN}$ nanopillars. ${ }^{36,37}$ AlN nanostructures have been fabricated in the form of nanofibers, ${ }^{41}$ nanorods, ${ }^{42,43}$ and nanowires, ${ }^{44-47}$ mainly using electrospinning, CVD, and molecular beam epitaxy (MBE) techniques. Similar to AlN, InN nanostructures have also been synthesized in the form of nanowires, ${ }^{48-56}$ nanoparticles, ${ }^{57-60}$ and nanorods ${ }^{61-65}$ using high-temperature epitaxial growth techniques (MOCVD, MBE).

A major limitation associated with the template-free synthesis strategy is the lower degree of control over the properties of 
the resulting structures. There may either exist additional unwanted morphologies or impurities in the final product which result in poor optical and electronic properties. It is of major significance to fabricate ordered nanostructures with superior regularity and large-area uniformity for tailoring semiconductor characteristics in a way to enhance the performance of nanostructured materials. Template-based methods are advantageous in the sense that a well-defined and long-range ordered sacrificial template can be used to guide the morphology of the nanostructures, which leads to their synthesis with controlled properties and largearea uniformity. Moreover, commonly used methods for the fabrication of III-nitride nanostructures employ high growth temperatures which can be lowered considerably by alternative low-temperature growth techniques.

Atomic layer deposition (ALD) is a specific vapor phase material deposition scheme that enables the conformal coating of thin films with sub-angstrom thickness control and excellent large-area uniformity. Besides being a ligand-preserving lowtemperature growth technique, its self-limiting characteristics offer precision thickness control at a sub-angstrom level with superior conformality and uniformity over arbitrary topography, large area, and complex three-dimensional nanostuctures. ${ }^{66-74}$ From this perspective, ALD becomes an attractive low-temperature material growth method to be used for template-assisted fabrication of nanostructured materials.

A variety of sacrificial templates can be employed as growth temperature decreases. Polymeric materials are famous sacrificial templates due to their design flexibility, availability, simple synthesis, and low cost. In one prominent strategy, polymeric electrospun nanofibers have been utilized as templates for subsequent ALD growth to fabricate long and uniform metal-oxide and nitride nanofibers with conformal and precise wall thickness control. ${ }^{75}$ The main drawback of electrospun nanofibrous templates is the randomness in the nanotemplate pattern; nanofibers are randomly oriented without any alignment. On the other hand, AAO membranes are another well-known class of templates that can be used to synthesize long-range ordered/aligned nanostructures with a high degree of regularity and uniformity. ${ }^{76}$ AAO membranes are advantageous to produce free-standing nanostructures as well as nanostructures attached/integrated to the host substrate. AAO membranes have been used as templates to produce GaN nanodot arrays, nanotubular materials, and porous GaN films where GaN growth is carried out via MOCVD. ${ }^{77}$ Using such a non-lithographic approach to fabricate arrays of nanostructures provides an attractive solution for large-area nano-patterning with relative process simplicity, high throughput, and low cost. Nevertheless, the reliability of nanostructures obtained using high aspect ratio templates is determined by the conformability of the thin film deposition process. On that note, ALD stands out as an ideal process that can be utilized to build nanostructures with very high aspect ratio templates owing to its superior conformality, uniformity, and atomic-scale thickness control. ALD has been previously used to grow III-nitride thin films where the impact of various growth parameters on film quality has been investigated in detail. $^{78-93}$
In this work, we demonstrate the precision fabrication of long-range ordered vertical GaN, AlN, and InN hollow nanocylindrical arrays on Si substrates using AAO membrane templated hollow-cathode plasma-assisted atomic layer deposition (HCPA-ALD). Uniform and vertically oriented nanocylinder arrays confirm the ability to precisely tune III-nitride nanostructure geometry via AAO-templated PA-ALD in comparison with other commonly used high-temperature growth techniques, which mainly allow one to obtain elongated nanostructures without three-dimensional precision thickness control. ${ }^{36-47}$ Ordered vertical GaN, AlN, and InN hollow nano-cylinder arrays have been characterized using scanning electron microscopy (SEM), energy dispersive X-ray analysis (EDX), transmission electron microscopy (TEM), selected area electron diffraction (SAED), grazing incidence X-ray diffraction (GIXRD), X-ray photoelectron spectroscopy (XPS), and photoluminescence (PL) measurements. The material properties of nanostructured III-nitride materials are compared with the thin-film counterparts, which were grown with the very same low-temperature HCPA-ALD technique on flat substrates.

\section{Experimental}

\section{(1) Vertical III-nitride hollow nanocylinder array fabrication}

The AAO foil fabrication process is explained in ESI. $\dagger$ The AAO membrane was attached to the $\mathrm{Si}(100)$ surface using triton liquid solution which helped to achieve better adhesion of the AAO membrane to the substrate surface and prevent possible membrane detachment during the subsequent fabrication steps. Triton was then removed from the surface using acetone and the surface was dried in conventional air ambient and at room temperature.

$\mathrm{Si}(100)$ was etched through AAO membrane hard masks in an RIE reactor using an $\mathrm{Ar}(100 \mathrm{sccm}) / \mathrm{CHF}_{3}(5 \mathrm{sccm})$ etch gas mixture for a total etch time of $70 \mathrm{~min}$. During Si etching, the coil and platen power were maintained at 450 and $100 \mathrm{~W}$, respectively. III-Nitride materials including GaN, AlN, and InN were deposited in a modified Fiji F200-LL remote-plasma ALD reactor (Ultratech/CambridgeNanoTech Inc.), which is backed by an Adixen ACP $120 \mathrm{G}$ dry scroll vacuum pump. The original system was revamped by replacing the quartz-based inductively coupled plasma (ICP) source with a stainless steel hollowcathode plasma (HCP) source (Meaglow Ltd, Thunder Bay, ON, Canada). The original RF power supply (Seren IPS Inc., R301), matching network controller (Seren IPS Inc., MC2), and automatic matching network (Seren IPS Inc., AT-3) units were used to activate the HCP discharge. The rotation speed of the Adixen ATH $400 \mathrm{M}$ turbo pump was adjusted in order to keep the reactor pressure fixed at $\sim 150$ mTorr during growth sessions, whereas the base pressure of the system was lower than $10^{-5}$ Torr. While the unit growth cycle for GaN consisted of a triethylgallium (TEG) pulse (0.5 s), an Ar purge (10 s), $\mathrm{N}_{2} / \mathrm{H}_{2}$ plasma exposure (60 s), and an Ar purge (10 s), one AlN ALD cycle was formed by a trimethylaluminum (TMA) pulse (0.06 s), an Ar purge (10 s), $\mathrm{N}_{2} / \mathrm{H}_{2}$ plasma exposure (40 s), and an Ar purge (10 s). For InN on the 
other hand, the unit growth cycle contained a trimethylindium (TMI) pulse $(0.07 \mathrm{~s})$, an Ar purge (10 s), $\mathrm{N}_{2}$ plasma exposure (100 s), and an Ar purge (10 s). $\mathrm{N}_{2} / \mathrm{H}_{2}$ or $\mathrm{N}_{2}$ plasma gas flow rates and plasma power were constant in all experiments at 50/50 $\mathrm{sccm}$ and $300 \mathrm{~W}$, respectively. Both $\mathrm{N}_{2}$ and Ar gases were of $99.998 \%$ purity and were further purified through Microtorr (MCL-702F) gas purifier units. All III-nitride growth experiments were performed at a substrate temperature of $200{ }^{\circ} \mathrm{C}$.

III-Nitrides deposited on the top of pores were removed in the RIE reactor using Ar (100 sccm) etching followed by selective etching of surrounding $\mathrm{Si}$ using a $\mathrm{SF}_{6}(60 \mathrm{sccm})$ etch recipe to obtain III-nitride hollow nanocylinders (HNCs). During both these etch steps, the coil and platen power were maintained at 450 and $100 \mathrm{~W}$, respectively. The schematic step-by-step fabrication of vertically aligned III-nitride HNCs is shown in Fig. 1.

\section{(II) Structural, chemical, surface, and optical characterization}

GIXRD patterns of III-nitride HNCs and thin films were recorded with an X'Pert PRO MRD diffractometer (PANalytical B.V., Almelo, Netherlands) using $\mathrm{Cu} \mathrm{K} \alpha$ radiation. Data were obtained within the $2 \theta$ range of $10-90^{\circ}$ using a $0.1^{\circ}$ step size and $15 \mathrm{~s}$ counting time. The elemental composition and chemical bonding states of III nitrides were determined by XPS using a Thermo Scientific K-Alpha spectrometer (Thermo Fisher Scientific, Waltham, MA) with a monochromatized $\mathrm{Al} \mathrm{K \alpha}$ X-ray source. Sputter depth profiling was performed on III-nitride thin films with a beam of Ar ions having an acceleration voltage and a spot size of $1 \mathrm{kV}$ and $400 \mu \mathrm{m}$, respectively. Surface morphologies of III-nitride HNCs at different stages of fabrication were revealed using SEM (FEI, Hillsboro, OR NNL 600i). A Tecnai G2 F30 TEM (FEI, Hillsboro, OR) was utilized for high-resolution (HR) imaging, EDX color mapping, and measurement of the SAED pattern of the III-nitride HNCs. In order to prepare TEM samples,
HNC samples were scratched by a needle and a TEM grid was gently touched to the top surface of the GaN-HNCs/nanoporous-Si samples followed by TEM imaging. PL spectra of the GaN HNCs and their thin film counterpart were measured in the wavelength range of $350-850 \mathrm{~nm}$ at room temperature and at a constant excitation laser intensity of $64 \mathrm{~W} \mathrm{~cm}^{-2}$. The samples were excited by a HeCd laser at $325 \mathrm{~nm}$ and the PL spectra were recorded with an Exemplar Plus BWTek spectrometer.

\section{Results and discussion}

The AAO membrane was used as a hard etch mask to transfer the pattern to the $\mathrm{Si}(100)$ substrate. The detail is provided in ESI $\dagger$ (Fig. S1). $\mathrm{CHF}_{3}$ and Ar were used to transfer the AAO honeycomb nano-porous pattern to the Si substrate. Ar acts as the physical sputtering agent responsible for the vertical anisotropic etch pattern. ${ }^{94}$ With the exposure of $\mathrm{CHF}_{3}$ plasma to the exposed Si surface, polymer forming radicals are deposited on the sidewalls, forming a barrier layer which prevents undercutting. A porous Si nano-network was formed by plasma etching through the AAO hard mask. Fig. S1e (ESI $\dagger$ ) reveals the highly ordered hexagonal array of nanopores formed on the Si surface, confirming the successful pattern transfer. The resulting average diameter of Si nanopores has increased to $\sim 90-100 \mathrm{~nm}$ due to the non-ideal anisotropic etch which results in a pore-widening effect, while the average pore-to-pore distance remains around $\sim$ 140-145 $\mathrm{nm}$. The density and size of the nanopores are rather close to the original AAO membrane template, which implies both the success of the pattern-transfer process and the ability to simply tune the pore size and morphology by modifying the initial anodization conditions. An angled-view image of the $\mathrm{Si}$ nano-porous structure is shown in Fig. S1f (ESI $\dagger$ ), which shows the depth of pores to be around $500 \mathrm{~nm}$.

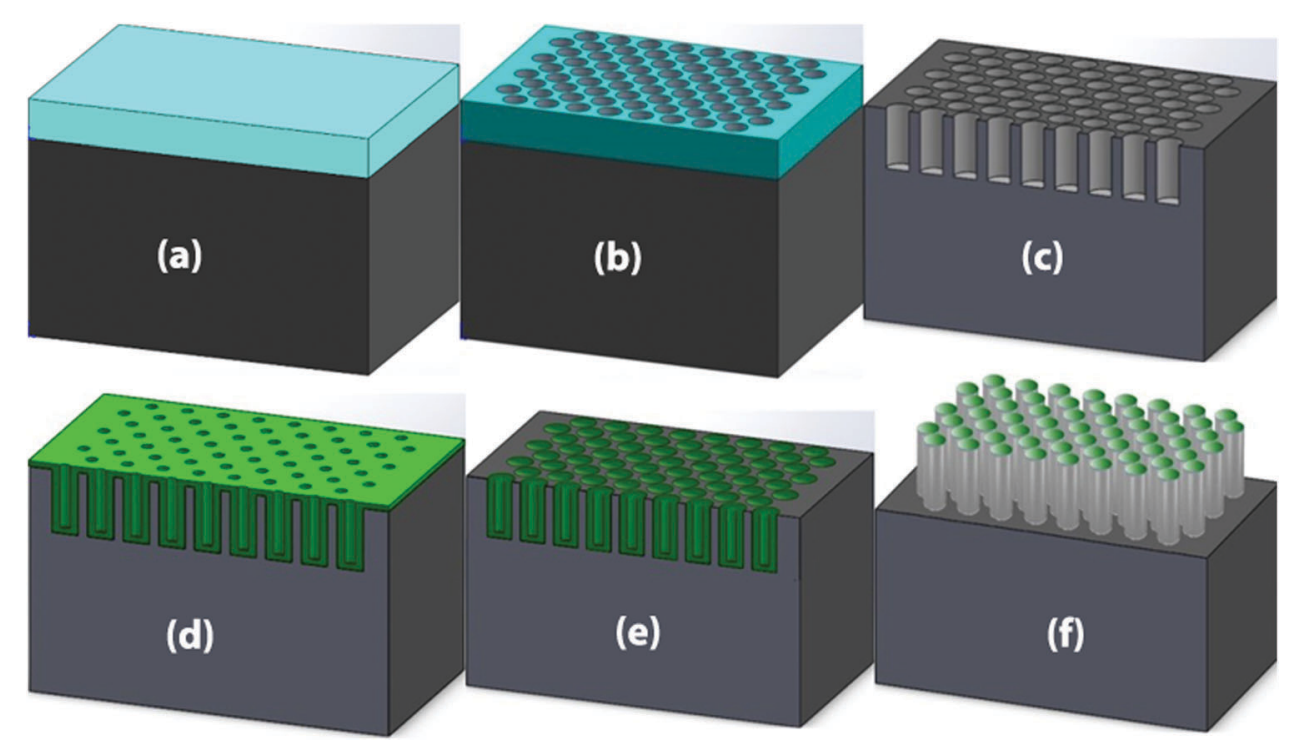

Fig. 1 The schematic showing step-by-step fabrication of vertically aligned III-nitride HNCs: (a) AAO membrane placement on Si(100), (b and c) Si patterning with $\mathrm{Ar} \mathrm{CHF}_{3}$ based reactive ion etching (RIE) using the AAO membrane as a hard mask material to achieve a nanoporous Si substrate,

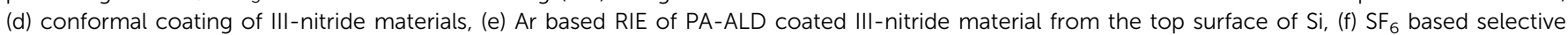
etching of Si to obtain III-nitride HNCs. 
III-Nitride material growth was carried out on a nanoporous Si substrate in a PA-ALD reactor featuring a customized hollowcathode plasma source. A critical factor in choosing ALD to grow on high aspect ratio porous $\mathrm{Si}$ is the superior conformality made possible by its self-limiting characteristics, which allow the surface to get saturated with no more than one layer of chemisorbed precursor molecules. Precursor molecules disperse into deep trench structures with sufficient precursor pulse/exposure time allowing molecules to react with the entire exposed surface. In the subsequent sections below, fabrication steps and material characterization details of GaN, AlN, and InN HNCs are provided.

\section{(I) GaN hollow nanocylinder arrays}

1500 cycles of GaN were grown on a nanoporous Si substrate via PA-ALD using TEG and $\mathrm{N}_{2} / \mathrm{H}_{2}$ plasma as gallium and nitrogen precursors, respectively. Fig. $2 \mathrm{a}$ and $\mathrm{b}$ show the top-view and angled-view SEM image after GaN growth on the nanoporous $\mathrm{Si}$ substrate, respectively. The grainy structure of GaN is visible from the top-view image (Fig. 2a) which was also observed in previously reported $\sim 32 \mathrm{~nm}$ thick GaN thin films on $\mathrm{Si}$ substrates. ${ }^{93}$ The porous morphology is still visible after GaN growth on Si nano-pores, however, the pore-size is reduced to $\sim 35 \mathrm{~nm}$. The ability of PA-ALD to uniformly coat GaN (thickness $\sim 37.5 \mathrm{~nm}$ ) on nano-porous $\mathrm{Si}$ in a conformal fashion is evident from the angled-view SEM image (Fig. 2b). The thickness of GaN observed from the inner walls of the nanoporous $\mathrm{Si}$ substrate is less than the GaN film thickness grown on a planar Si substrate $(\sim 37.5 \mathrm{~nm} v s .50 \mathrm{~nm})$ in the same growth experiment. The thickness variation of GaN along the Si pore depth is $\pm 24-25 \%$. ALD, with its inherent self-limiting growth mechanism, is expected

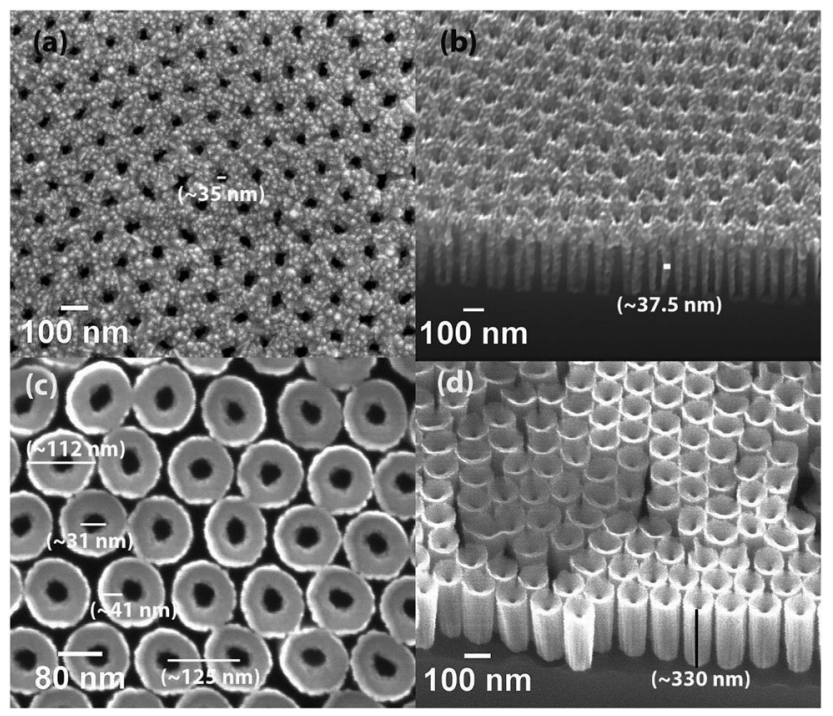

Fig. 2 (a) Top view SEM image obtained from PA-ALD (1500 cycles) grown GaN on a nanoporous Si substrate, (b) angled-view SEM image of the same sample showing the rather conformal filling of GaN into the $\mathrm{Si}$ nanopores, (c) top-view SEM image of GaN HNCs revealing their morphology and dimensions, and (d) angled-view SEM image of GaN HNCs showing the total height of the nano-cylinders. to provide highly conformal non-line of sight deposition even on 3D complex nanostructures. However, ideal conformal coating results for ALD-growth on nanostructured templates can only be achieved by carefully optimizing the process parameters such as precursor doses, exposure time, and purging time at a given reaction temperature. A substrate must be exposed to the right amount of precursor as an insufficient precursor dose will leave some unreacted surface sites behind, resulting in limited conformality. The most critical parameter in performing ALD on substrates with higher aspect ratio structures is the precursor exposure time. With sufficient precursor exposure time, precursor molecules should be able to reach all the active sites on the 3D substrate surface. Generally, long precursor exposures are relatively less beneficial in plasma-assisted ALD due to the relatively fast plasma radical recombination process. In the present work, we have utilized the PA-ALD growth recipe previously optimized for planar Si surfaces. ${ }^{93}$ An additional significant effort needs to be devoted to achieve ideal conformal deposition via PA-ALD which is beyond the scope of the present study.

As GaN film grows on the horizontal top surface of Si nanopores as well, those parts must be removed before Si etching can be carried out to obtain free-standing GaN nano-cylindrical arrays on the Si surface. The SEM image (Fig. S2, ESI $\dagger$ ) showed that 2 minutes of Ar plasma exposure successfully removed GaN from the top of the nano-pores. The last step in fabrication was to selectively etch Si via $\mathrm{SF}_{6}$ plasma to obtain GaN HNCs. Fig. 2c and d show the top-view and angled-view SEM images of GaN HNCs after $6 \mathrm{~s}$ of $\mathrm{SF}_{6}$ based Si etching, respectively. The diameter of GaN nano-cylinders is $\sim 110 \mathrm{~nm}$, while the pore size within the HNC is about $30 \mathrm{~nm}$. The wall thickness of individual HNCs and inter-cylinder distance were measured as $\sim 40$ and $\sim 125 \mathrm{~nm}$, respectively. By changing the etching time of $\mathrm{Si}$, the height of free-standing individual GaN nanocylinders can be varied as well. After $6 \mathrm{~s}$ of Si etching, the height of GaN HNCs ranged within $\sim 330-360 \mathrm{~nm}$, corresponding to HNCs with a $3: 1$ aspect ratio.

TEM characterization was carried out on GaN HNCs to examine their internal morphology and crystalline structure. Bright field TEM images of GaN HNCs are provided in Fig. 3. Finely dispersed hollow nano-cylinders can be seen in Fig. 3a. Fig. 3b confirms the total length of GaN HNCs at around $\sim 375 \mathrm{~nm}$ and shows that their interior is indeed hollow. It is observed that the outer wall of HNCs is highly uniform along the cylinder axis. However, the wall thickness of GaN HNCs along the long axes of individual cylinders shows a degree of non-uniformity. The part where the GaN wall is thicker corresponds to the top portion of the HNC close to the air-HNC interface. This image reveals that GaN wall thickness tends to become thinner along the depth of the Si pore. As explained earlier, this might either be due to insufficient precursor exposure and/or $\mathrm{N}_{2} / \mathrm{H}_{2}$ plasma radical-recombination during HCPA-ALD of GaN. Fig. 3c shows the high-resolution TEM (HRTEM) image of HNCs, revealing lattice fringes of GaN which are organized in various crystallographic orientations confirming its polycrystalline structure. Selected area electron diffraction (SAED) measurements were performed to further investigate the crystal structure of the GaN HNCs. The SAED pattern (Fig. 3d) 

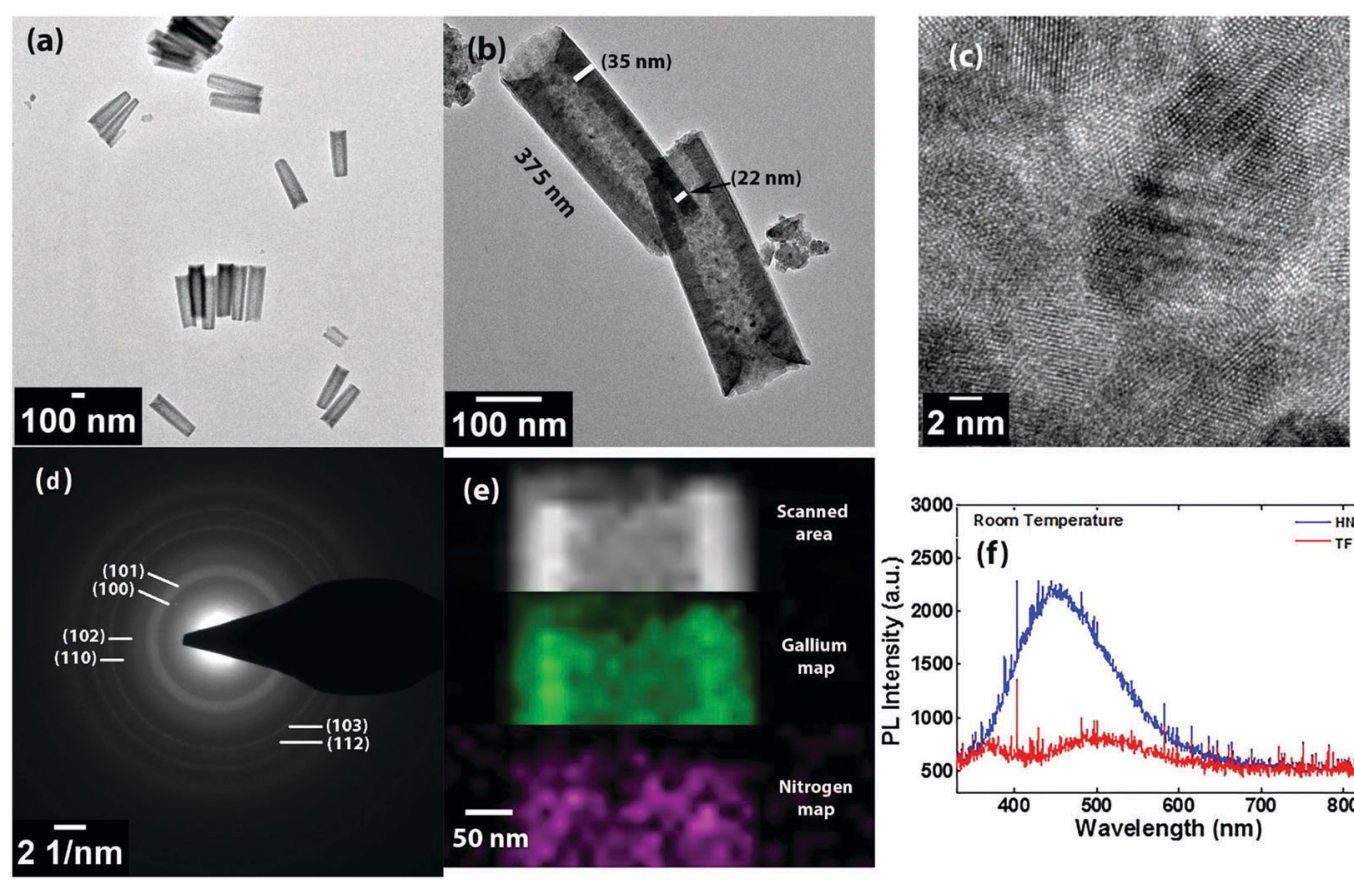

Fig. 3 (a) TEM image of several individual and bundled GaN HNCs, (b) TEM image of GaN HNCs revealing their wall thickness and total length, (c) HRTEM image of a GaN HNC displaying the polycrystalline structure of PA-ALD grown GaN, (d) SAED pattern of GaN HNCs, (e) EDX elemental mapping of the same GaN HNC sample, and (f) PL spectra of GaN HNCs and 60 nm thick GaN thin film (TF) gathered at room temperature.

consists of polycrystalline diffraction rings corresponding to the hexagonal wurtzite GaN (h-GaN) crystal structure. The analysis of the SAED pattern has been summarized in Table 1, which shows measured ring diameters, the calculated and theoretical interplanar spacing values, and corresponding crystallographic planes. The first ring from the center is considerably thick and the theoretical ring diameters of the (101), (100), and (002) crystallographic planes either merge or lie very close to the first thick diffraction ring. Indeed, the inner and central diameters of this ring were measured and found to be 7.509 and $8.501 \mathrm{~nm}^{-1}$, corresponding to the (100) and (101) planes with calculated inter-planar spacing $\left(d_{h k l}\right)$ values of 2.663 and $2.395 \AA$, respectively. Other than the (100) and (101) crystallographic planes, the (102), (101), (103), and (112) planes corresponding to the GaN hexagonal wurtzite crystal structure are also found.

Fig. 3e shows EDX elemental mapping of gallium and nitrogen from a part of an individual GaN HNC. This measurement reveals

Table 1 SAED results, theoretical values, and corresponding crystallographic planes

\begin{tabular}{llll}
\hline & \multicolumn{2}{l}{ Interplanar spacing, $d_{h k l}(\AA)$} & \\
\cline { 2 - 3 } Diameter $\left(\mathrm{nm}^{-1}\right)$ & Calculated & Theoretical $^{a}$ & $\begin{array}{l}\text { Corresponding } \\
\text { plane }^{a}, h k l\end{array}$ \\
\hline 7.509 & 2.663 & 2.7620 & 100 \\
8.501 & 2.395 & 2.4370 & 101 \\
10.588 & 1.888 & 1.8910 & 102 \\
12.059 & 1.658 & 1.5945 & 110 \\
13.526 & 1.478 & 1.4649 & 103 \\
14.864 & 1.345 & 1.3582 & 112
\end{tabular}

${ }^{a}$ Hexagonal GaN, ICDD reference code: 00-025-1133. the uniform distribution of gallium and nitrogen which confirms the presence of a GaN compound structure in the scanned area. The PL spectra of polycrystalline GaN HNCs and their thin film counterpart were measured in the wavelength range $350-850 \mathrm{~nm}$ at room temperature and are presented in Fig. 3f. A broad peak at $448 \mathrm{~nm}(2.76 \mathrm{eV})$ was observed from GaN HNCs, which represents a defect related "blue luminescence (BL)" emission. On the other hand, a weak and noisy signal was observed from $\sim 60 \mathrm{~nm}$ thick GaN thin films which exhibited two relatively weaker peaks at $371.3 \mathrm{~nm}(3.34 \mathrm{eV})$ and $500 \mathrm{~nm}(2.48 \mathrm{eV})$, most probably originating from a red shifted band-edge-related emission and structural defect sourced "green luminescence (GL)", respectively. ${ }^{95,96}$ The presence of the "GL" band could be explained by the combination of gallium vacancy clusters and oxygen (or carbon) impurities. ${ }^{96}$ GaN HNCs exhibit a stronger PL signal than their thin-film counterparts possibly due to their higher surface to volume ratio.

GIXRD patterns of GaN HNCs and GaN thin film deposited on $\mathrm{Si}$ are provided in Fig. 4a and b, respectively. Patterns obtained from both GaN HNCs and the corresponding thin film reveal the single-phase polycrystalline hexagonal wurtzite structure. The reflections (100), (002), (101), (101), (103), and (112) of the h-GaN phase appeared in the GIXRD patterns (hexagonal GaN, ICDD reference code: 00-025-1133). These results are in good agreement with the SAED results given in Fig. $3 \mathrm{~d}$ and Table 1 . A distinct (002) reflection was not observed in the SAED diffraction pattern, however, we believe that it is not distinguishable in the SAED pattern due to the merging of three individual diffraction rings into one big thick ring closest from the center. 

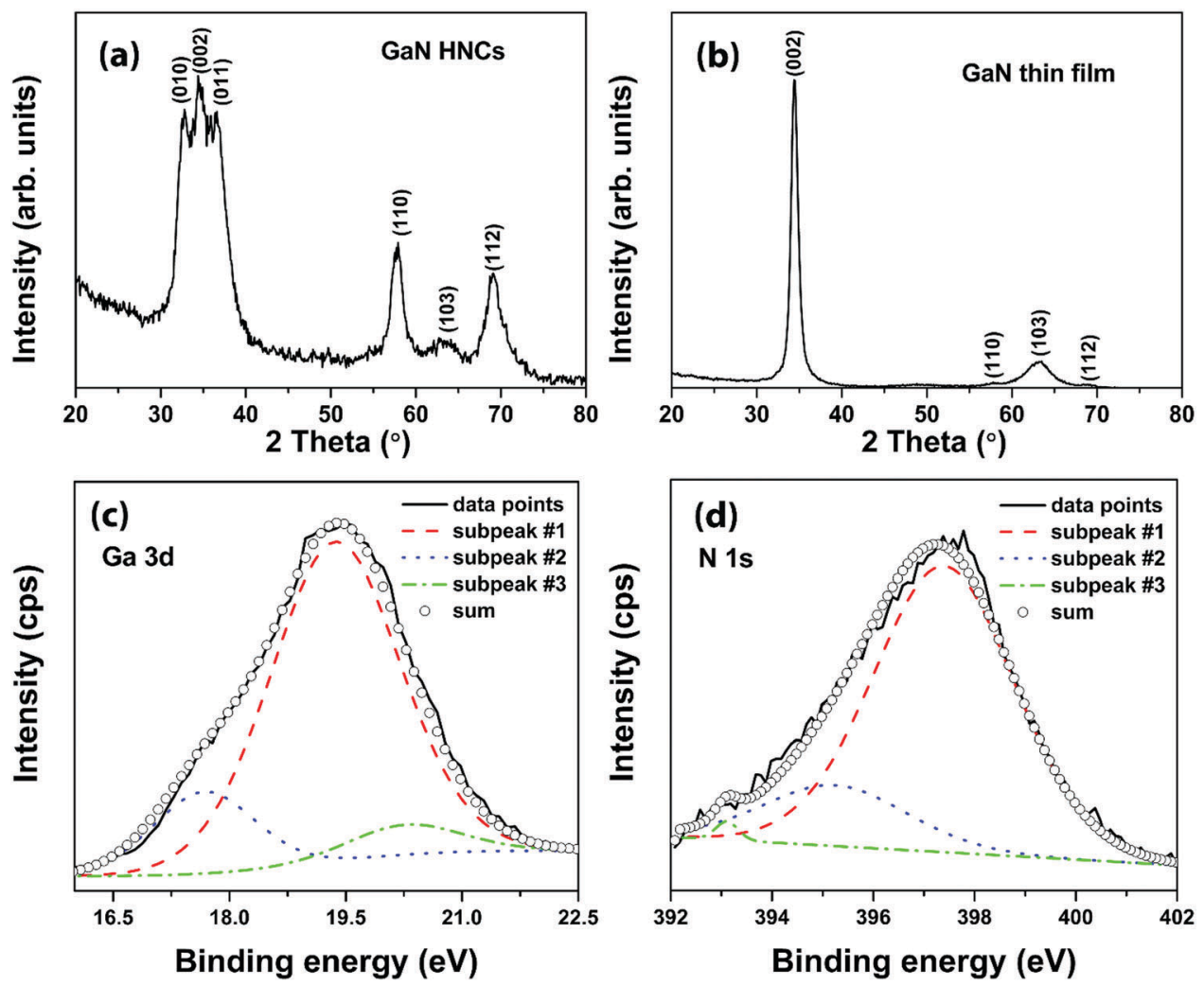

Fig. 4 GIXRD pattern obtained from (a) GaN HNCs grown on nanoporous Si substrates, (b) $~ 50$ nm thick GaN deposited on planar Si via HCPA-ALD, HR-XPS scans of (c) Ga 3d and (d) N 1s obtained from GaN HNCs revealing the presence of various bonding schemes.

The chemical composition and bonding state of GaN HNCs were studied using X-ray photoelectron spectroscopy (XPS). An XPS survey scan collected from the top of $\sim 375 \mathrm{~nm}$ long GaN HNCs revealed the presence of gallium, nitrogen, carbon, fluorine, and oxygen elements. The atomic percentages of elements detected from GaN HNCs were as follows: 33.21 at $\%$ Ga, 45.08 at\% N, 5.74 at\% C, 5.64 at\% F, and 10.33 at\% O. Although these results suggest N-rich elemental distribution in GaN HNCs, it should be noted that the atomic concentration of $\mathrm{N}$ is overestimated due to the significant contribution of $\mathrm{Ga}$ Auger peaks, which overlap with the N 1s peak. ${ }^{84}$ Previously, we have reported the impurity content from the bulk of GaN thin film deposited using the exact same PA-ALD growth recipe parameters utilized for fabrication of GaN HNCs. No carbon was found in the bulk of the film, while oxygen impurities (2-3 at\%) in the bulk of GaN films were detected. The presence of oxygen in the bulk of the film was attributed to oxygen and water vapor impurities present in either plasma gases or organometallic precursors and trapped oxygen/water vapor inside the multilayer coatings on the inner walls of the ALD vacuum reactor. XPS was used to gather data from the bulk of the film by in situ etching of the first few layers of GaN via $\mathrm{Ar}^{+}$ions. The same technique, however, would not be accurate to determine the GaN bulk impurity content from GaN HNCs due to possible oxidation of GaN HNCs all along the top surface. Therefore, bulk elemental quantification from the GaN thin film sample can be used as an estimate for the impurity content of GaN HNCs.
High-resolution XPS (HR-XPS) scans of Ga $3 \mathrm{~d}$ and $\mathrm{N}$ 1s are given in Fig. 4c and d, respectively, which were collected from the surface of GaN HNCs. The asymmetry and FWHM of the peaks indicate more than one type of bonding scheme for both gallium and nitrogen. The Ga 3d HR-XPS spectrum was fitted using three subpeaks located at $20.30 \mathrm{eV}$ (subpeak \#3), $19.38 \mathrm{eV}$ (subpeak \#1) and $17.68 \mathrm{eV}$ (subpeak \#2). Subpeaks number 1 and 3 were attributed to the $\mathrm{Ga}-\mathrm{N}$ and $\mathrm{Ga}-\mathrm{O}$ bonds, respectively, whereas subpeak \#2 originates from the N2s core level contribution. ${ }^{85}$ The N 1s HR-XPS spectrum (Fig. 4d) was fitted by three subpeaks located at $397.37 \mathrm{eV}$ (subpeak \#1), $395.18 \mathrm{eV}$ (subpeak \#2) and $393.08 \mathrm{eV}$ (subpeak \#3). Subpeak \#1 was assigned to the $\mathrm{N}-\mathrm{Ga}$ bond, whereas subpeaks \#2 and \#3 correspond to the Ga Auger peaks. ${ }^{84}$

\section{(II) AlN hollow nanocylinder arrays}

For AlN samples, a total of 500 ALD cycles were used on nanoporous Si substrates. A detailed growth optimization study of AlN on a planar Si template has been reported elsewhere. ${ }^{84}$ At $200{ }^{\circ} \mathrm{C}$, a growth rate of $\sim 1.0 \AA$ per cycle has been reported for AlN deposited with an optimized growth recipe, which corresponds to $\sim 50 \mathrm{~nm}$ thick film for 500 ALD-cycle growth on planar Si.

Fig. S4(a) and (b) (ESI $\dagger$ ) show top and angled-view SEM images of the AlN-coated nanoporous Si template, respectively. AlN covered Si shows a hollow morphology, though the pore size has been reduced to $\sim 30 \mathrm{~nm}$ from an initial pore diameter 
of $\sim 100 \mathrm{~nm}$ after nanopore formation. The top-view image also shows nanometer sized grains of AlN observed in the area amid the pores. The angled-view SEM image Fig. S4(b) (ESI $\dagger$ ) of AIN covered porous Si reveals uniform and conformal growth of AIN inside the nanopores. From the inner cylinder wall, the average wall thickness of AlN was measured as $\sim 37 \mathrm{~nm}$. The variation in AlN thickness from the top to the bottom of the pores is about $\pm 15 \%$.

SEM images (Fig. S3, ESI $\dagger$ ) obtained after 3 minutes of $\mathrm{Ar}$ etching indicate that AlN has been completely removed from the top surface. As a last step in AlN HNC fabrication, Si was selectively etched by $\mathrm{SF}_{6}$ gas to obtain free-standing AlN HNCs on the Si surface. $5 \mathrm{~s}$ of Si etching yielded $\sim 110 \mathrm{~nm}$ long AlN HNCs (Fig. S5, ESI $\dagger$ ) with a diameter and internal pore size of $\sim 116$ and $\sim 30 \mathrm{~nm}$, respectively. A significant portion of AlN is still embedded inside Si after $5 \mathrm{~s}$ of etching. In order to further increase the height of AlN HNCs, a total of $7 \mathrm{~s}$ Si etching was employed on a separate sample. Fig. S4c and d (ESI $\dagger$ ) show the top-view and angled-view SEM images of AlN HNCs, respectively, after $7 \mathrm{~s}$ of $\mathrm{SF}_{6}$ based Si etching. Long-range ordered AlN HNCs in well-organized arrays can be observed from the top and cross sectional views. The nano-cylinder diameter and internal pore size of AlN HNCs were measured as $\sim 115 \mathrm{~nm}$ and $\sim 25 \mathrm{~nm}$, respectively. The AlN wall thickness of individual nanocylinders and the inter-pore distance were measured as $\sim 45$ and $\sim 130 \mathrm{~nm}$, respectively. The height of AlN HNCs (Fig. S4(d), ESI $\dagger$ ) increased to $\sim 170 \mathrm{~nm}$ after $7 \mathrm{~s}$ of Si etching.

The internal morphology and crystalline structure of AlN HNCs are observed with TEM analysis as shown in Fig. 5.
AlN HNCs exhibited hollow morphology and rather smooth outer walls (Fig. 5b). Similar to GaN HNCs, the uniformity degree of the AlN HNCs wall thickness is limited. The thickness of AlN measured from two ends of an AlN HNC is $\sim 44 \mathrm{~nm}$ and $\sim 31 \mathrm{~nm}$ which corresponds to a $\pm 13 \%$ overall thickness non-uniformity. The total length of an individual AlN HNC was measured to be $\sim 172 \mathrm{~nm}$ which agrees very well with SEM measurements. Several crystalline compartments of AlN can be observed from the HR-TEM image of an AlN HNC (Fig. 5c), implying the polycrystalline structure of $\mathrm{AlN}$, similar to the observations for the GaN and InN HNC samples. EDX elemental maps (Fig. 5d and e) were obtained to map the presence of aluminum and nitrogen from AlN HNCs. This colored EDX mapping shows that aluminum and nitrogen are uniformly present only at the place of an AlN HNC in the scanned area. The SAED pattern (Fig. 5f) was extracted from $\sim 172 \mathrm{~nm}$ long AlN HNCs, which shows multiple diffraction rings confirming the polycrystalline structure of AlN. The diameters of the rings and calculated-theoretical interplanar spacing values are tabulated in Table 2, revealing the presence of the (100), (002), (101), (102), (110), (102), and (112) reflections of hexagonal AlN.

The structural and chemical properties of AlN HNCs were studied using GIXRD and XPS. The details are presented in Fig. S6 and S7 (ESI $\dagger$ ). In summary, structural characterization data using GIXRD revealed the polycrystalline nature of AlN HNCs whereas chemical characterization confirmed the presence of an $\mathrm{Al}-\mathrm{N}$ bonding state along with low impurity (carbon and oxygen) content.

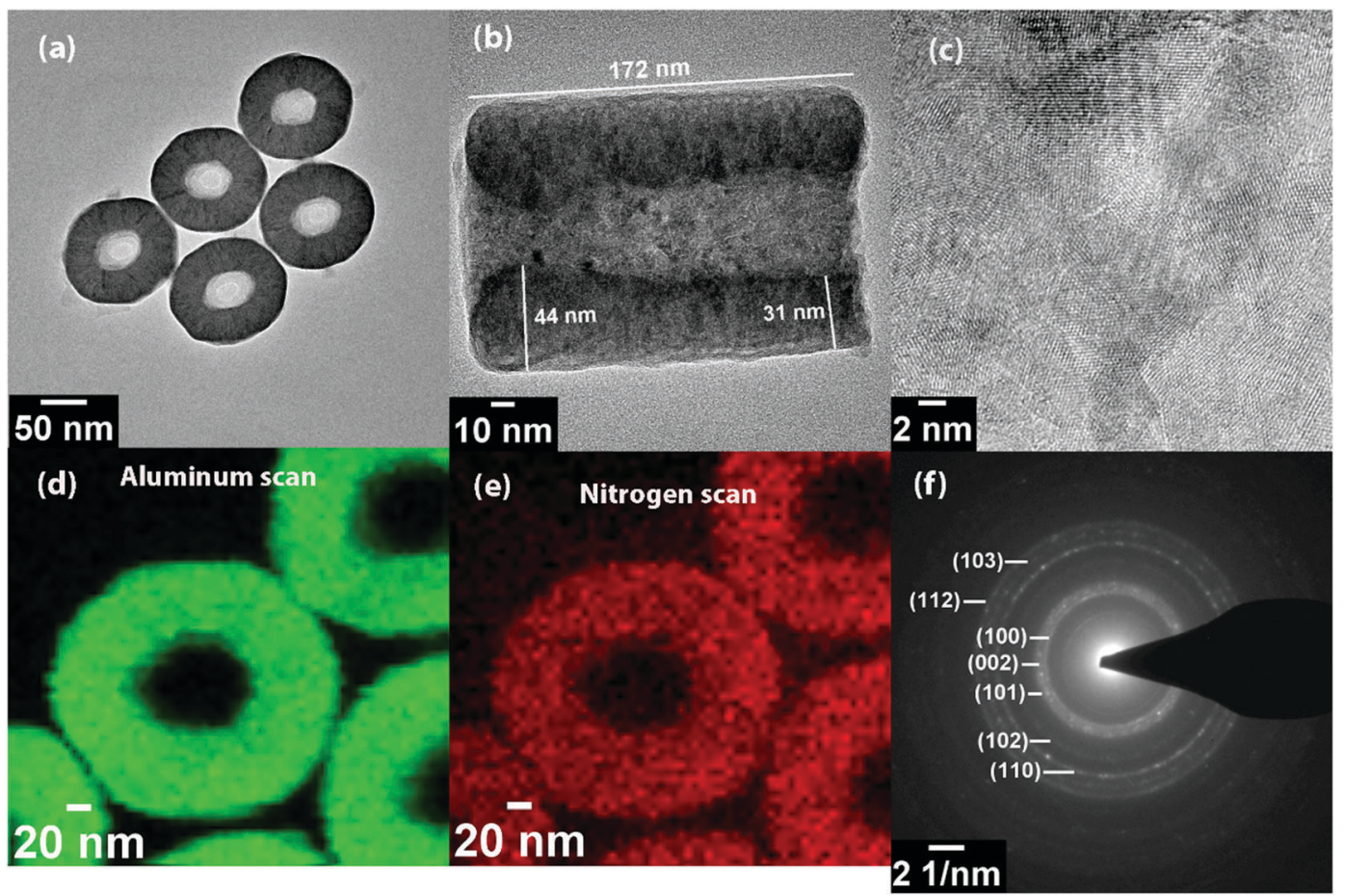

Fig. 5 (a) TEM image of AIN HNCS, (b) TEM image of an individual AIN HNC revealing the thickness and total length, (c) HR-TEM image of an AIN HNC displaying the internal crystal structure of AIN, (d) EDX elemental map of aluminum, (e) EDX elemental map of nitrogen, and (f) SAED pattern of AIN HNC samples. 


\section{(III) InN hollow nanocylinder arrays}

700-Cycle PA-ALD growth of InN was carried out on a nanoporous Si template using an optimized recipe with TMI and $\mathrm{N}_{2}$ plasma as an indium and a nitrogen source, respectively. The InN PA-ALD growth recipe that is utilized in this study was optimized for planar Si substrates and is reported elsewhere. ${ }^{81}$ It was found that InN grown using $\mathrm{N}_{2}$ plasma only as the nitrogen precursor had decent crystalline quality with low impurity content. InN grown with other plasma combinations such as $\mathrm{N}_{2} / \mathrm{H}_{2}$ plasma as the nitrogen precursor resulted in low density films with significant voids and weak surface adherence.

Fig. $6 \mathrm{a}$ and $\mathrm{b}$ show top and angled-view SEM images of InN-coated nanoporous Si templates, respectively. The highly uniform grainy structure of InN (Fig. 6a) is visible with a relatively smooth surface morphology. The nanopores are still apparent, however the pore size is significantly reduced $(\sim 25 \mathrm{~nm})$ from the original pore size in Si. The angled-view SEM image (Fig. 6b) reveals that InN is coated with high conformality along the wall depth of the pores. One can also observe that some of the initially narrower nanopores are indeed completely filled with InN, transforming these structures from hollow nanocylinders to nanopillars/nanorods. The wall thickness of InN nanocylinders was measured to be $\sim 43 \mathrm{~nm}$, which is very close to the measured $\mathrm{InN}$ film thickness $(\sim 47 \mathrm{~nm})$ on a planar $\mathrm{Si}$ substrate grown during the same ALD experiment. This indicates that the conformality of InN deposited on porous Si with a growth recipe optimized for a planar Si substrate is substantially better when compared to the conformality performance of GaN.

InN grown on the horizontal Si surface of the nanoporous $\mathrm{Si}$ substrate has been etched away using Ar ion milling. Subsequent SEM imaging (Fig. S8, ESI $\dagger$ ) revealed complete removal of the top InN layer after 3 minutes of Ar plasma exposure. Fig. $6 \mathrm{c}$ and $\mathrm{d}$ show the top-view and angled-view SEM images of InN HNCs after $7 \mathrm{~s}$ of $\mathrm{SF}_{6}$ etching in the RIE reactor, respectively. Both SEM images reveal long-range ordered and well-aligned InN HNC arrays. The wall thickness and pore diameter of an individual InN HNC are measured as $\sim 50$ and $\sim 15 \mathrm{~nm}$, respectively, while the pore-to-pore distance was found to be $\sim 115 \mathrm{~nm}$. After 7 seconds of Si etching, the height of InN HNCs (Fig. 6d) was measured as $\sim 220 \mathrm{~nm}$. InN HNCs were also fabricated with $6 \mathrm{~s}$

Table 2 SAED pattern analysis of AIN HNCs: comparison between measured and theoretical values of interplanar spacing $\left(d_{h k l}\right)$ with corresponding crystallographic planes

\begin{tabular}{llll}
\hline & \multicolumn{2}{l}{$\begin{array}{l}\text { Interplanar } \\
\text { spacing, } d_{h k l}(\AA)\end{array}$} & \\
\cline { 2 - 3 } Diameter $\left(\mathrm{nm}^{-1}\right)$ & Calculated & Theoretical $^{a}$ & $\begin{array}{l}\text { Corresponding } \\
\text { plane, } h k l\end{array}$ \\
\hline 7.504 & 2.665 & 2.6950 & 100 \\
8.154 & 2.452 & 2.490 & 002 \\
8.625 & 2.318 & 2.371 & 101 \\
11.108 & 1.800 & 1.829 & 102 \\
12.984 & 1.540 & 1.555 & 110 \\
14.242 & 1.404 & 1.413 & 103 \\
15.467 & 1.293 & 1.319 & 112
\end{tabular}

${ }^{a}$ Hexagonal AlN, ICDD reference code: 00-025-1133.

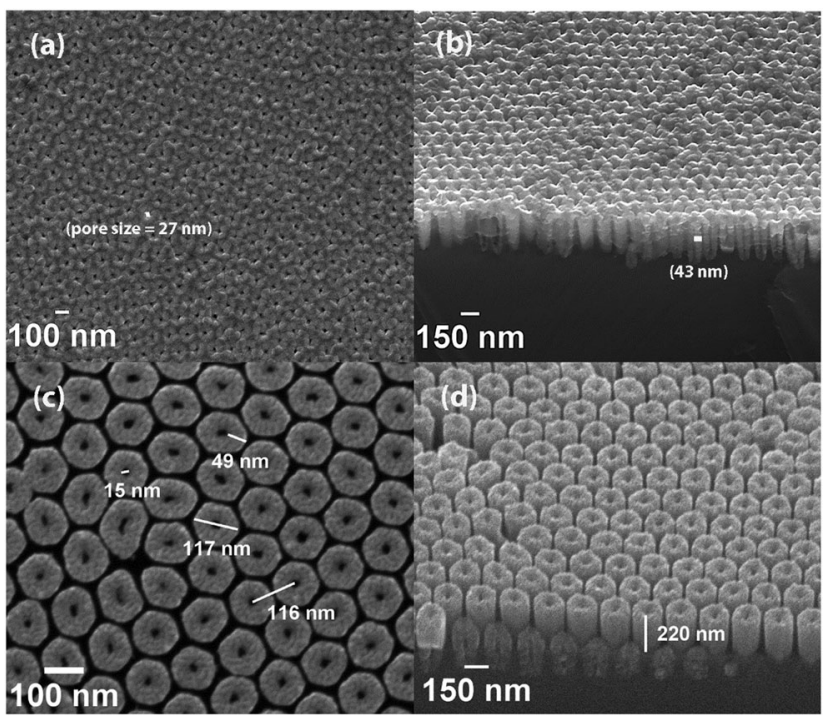

Fig. 6 (a) Top view SEM image obtained from PA-ALD (700-cycle) grown InN on a nanoporous Si substrate, (b) angled-view SEM image of the same sample, (c) top view SEM image of InN HNCs revealing their morphology and dimensions, and (d) angled-view SEM image of InN HNCs showing the free-standing height of $\mathrm{InN}$ nanocylinders.

of Si etching using $\mathrm{SF}_{6}$ followed by SEM imaging (Fig. S9, ESI $\dagger$ ). The nano-cylinder diameter, pore size, wall thickness, and poreto-pore distance (Fig. S9, ESI $\dagger$ ) of this set of HNCs were found to be similar to InN HNCs fabricated using $7 \mathrm{~s}$ of $\mathrm{Si}$ etching. However, as expected, the height of InN HNCs fabricated using $6 \mathrm{~s}$ of Si etching is reduced to $\sim 170 \mathrm{~nm}$. This result confirms that the final free-standing height of HNCs fabricated using this technique can be varied as desired by adjusting the etch time of $\mathrm{Si}$ in the final fabrication step.

The internal morphology of InN HNCs can be observed in the TEM images provided in Fig. 7. Fig. 7a shows the top-view of several InN HNCs with hollow internal morphology. The dimensions of HNCs such as the cylinder diameter, pore size, wall thickness, and inter-pore distance seen in this TEM image are similar to the observed dimensions in the SEM images shown in Fig. 6.

Fig. 7b shows the TEM image of two HNCs. The length of the InN HNC measured from this TEM image is $\sim 204 \mathrm{~nm}$ which is close to the height observed from the SEM image. It can be observed that the outer wall of HNCs is quite uniform along the cylinder axes. Contrary to GaN and AlN HNCs, the wall thickness of InN HNCs along the cylinder long axis is decently constant. The wall thickness measured from two ends of the HNCs came out as $\sim 41.7$ and $\sim 42.4 \mathrm{~nm}$ which corresponds to less than $\pm 1.0 \%$ variation in the wall thickness along the height of the HNC. This observation confirms the superior InN conformality compared to the GaN counterparts. It has been reported in the literature that the recombination loss probability ( $r$ ) of hydrogen radicals is generally higher than that of nitrogen radicals on different materials (on $\mathrm{Si}, 0.0016$ vs. 0.70 for nitrogen and hydrogen radicals, respectively). ${ }^{97}$ This means, for instance, a hydrogen radical has higher probability to recombine with a hydrogen atom on the surface to form 


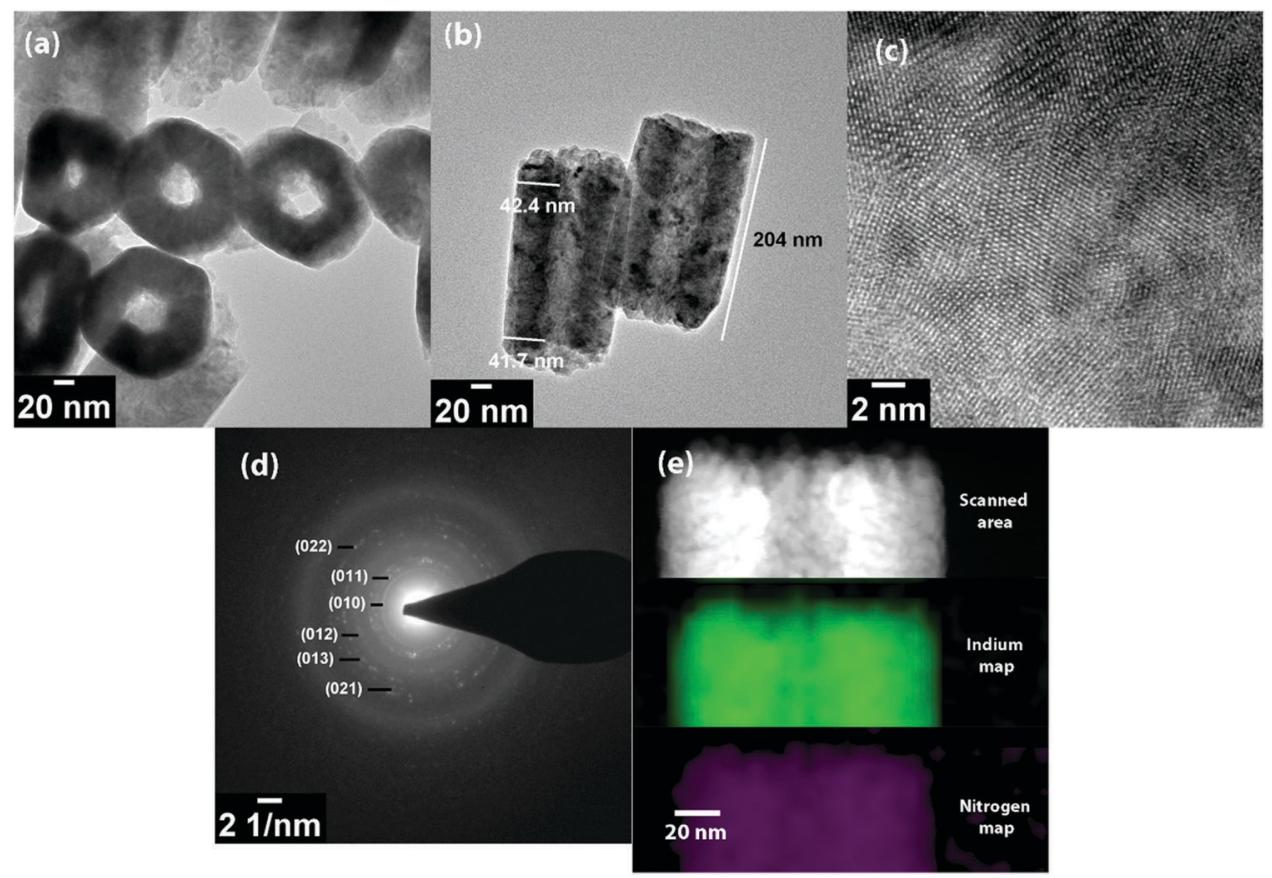

Fig. 7 (a) TEM image of InN bundled HNCs, (b) TEM image of InN HNCs revealing their wall thickness and total length, (c) HR-TEM image of InN HNC displaying the internal crystal structure and confirming the polycrystalline nature, (d) SAED pattern of InN HNCs, and (e) EDX elemental mapping of the same sample.

molecular hydrogen. This hydrogen molecule will then have no further influence on the ALD surface reactions. As nitrogenonly plasma has been used for InN growth compared to $\mathrm{N}_{2} / \mathrm{H}_{2}$ plasma for the GaN and AlN experiments, the observed enhanced conformality of InN can be partly attributed to the lower recombination loss probability of nitrogen radicals. ${ }^{97}$

Fig. 7c shows the HR-TEM image of a selected InN HNC. Several crystalline subsections of InN can be observed, while in each crystalline subsection, lattice fringes are organized in different orientations implying a polycrystalline structure. Fig. $7 d$ shows the SAED pattern of InN HNCs which exhibits several diffraction rings confirming the polycrystalline structure of InN. The interplanar spacing $\left(d_{h k l}\right)$ values of the diffraction rings were calculated and compared with theoretical values to identify the associated crystallographic orientations. Table 3 shows that the (010), (011), (012), (013), (021), and (022) reflections of the

Table 3 SAED pattern analysis of InN HNCs: comparison between measured and theoretical values of interplanar spacing $\left(d_{h k l}\right)$ with corresponding crystallographic planes

\begin{tabular}{llll}
\hline & \multicolumn{2}{l}{$\begin{array}{l}\text { Interplanar } \\
\text { spacing, } d_{h k l}(\AA)\end{array}$} & \\
\cline { 2 - 3 } Diameter $\left(\mathrm{nm}^{-1}\right)$ & Calculated & Theoretical $^{a}$ & $\begin{array}{l}\text { Corresponding } \\
\text { plane, } h k l\end{array}$ \\
\hline 6.501 & 3.076 & 3.062 & 010 \\
7.396 & 2.704 & 2.698 & 011 \\
9.850 & 2.030 & 2.088 & 012 \\
12.455 & 1.605 & 1.616 & 013 \\
13.708 & 1.459 & 1.478 & 021 \\
15.047 & 1.329 & 1.349 & 022
\end{tabular}

${ }^{a}$ Hexagonal InN, ICDD reference code: 00-050-1239. hexagonal structure of polycrystalline InN are detected. Fig. 7e shows EDX elemental maps of indium and nitrogen obtained from the InN HNC sample. Indium and nitrogen show strong contrast in the colorized maps which prove their uniform presence within the scanned area.

The structural and chemical properties of InN HNCs were further investigated by GIXRD and XPS analysis, of which the details are presented in Fig. S10 and S11 (ESI†). GIXRD analysis confirmed the single-phase hexagonal crystalline structure of InN HNCs whereas XPS showed the presence of In-N bonding and the existence of oxygen impurities.

\section{Conclusions}

Template-based synthesis of long-range ordered GaN, AlN, and InN vertical hollow nanocylinder arrays was demonstrated via low-temperature plasma-assisted ALD and etching processes on Si substrates. In-depth morphological, optical, structural, and chemical characterization was performed to investigate the material properties of the fabricated III-nitride HNCs. SEM images revealed the successful fabrication of long-range ordered arrays of III-nitride HNCs integrated on Si. TEM, GIXRD, and SAED revealed that III-nitride HNCs possess the hexagonal wurtzite crystalline structure. Chemical analysis conducted using XPS via survey and HR-scans confirmed the successful fabrication of III-nitride HNCs with relatively low impurity content. The unique advantages of the proposed methodology include Si-integration due to low-temperature plasma-assisted growth and nanometer-level precision processing enabling fine control of the targeted nanostructures. Although single-layered binary compound nanostructures 
are demonstrated in this study, the methodology proposed can be applied for multi-layered heterostructures (GaN/AlN, InN/ $\mathrm{GaN}$, etc.) as well as ternary compounds (AlGaN/GaN, InGaN/ $\mathrm{GaN}$ ), resulting in alternative quantum-device structures. Such long-range ordered high-surface area III-nitride HNCs might potentially be used in various applications including piezotronic environmental sensing, III-nitride photovoltaic solar cells, wearable and flexible electronics, plasmonics, and (photo)catalysis.

\section{Conflicts of interest}

There are no conflicts to declare.

\section{References}

1 G. Yuan, K. Xiong, C. Zhang, Y. Li and J. Han, ACS Photonics, 2016, 3, 1604-1610.

2 Y. F. Cheung, K. H. Li and H. W. Choi, ACS Appl. Mater. Interfaces, 2016, 8, 21440-21445.

3 K. Chung, H. Yoo, J. K. Hyun, H. Oh, Y. Tchoe, K. Lee, H. Baek, M. Kim and G. C. Yi, Adv. Mater., 2016, 28, 7688-7694.

4 A. Fadil, Y. Ou, D. Iida, S. Kamiyama, P. M. Petersen and H. Ou, Nanoscale, 2016, 8, 16340-16348.

5 V. Thakur, S. Siddhanta, C. Narayana and S. M. Shivaprasad, RSC Adv., 2015, 5, 106832-106837.

6 M. Bańkowska, J. Krajczewski, I. Dziecielewski, A. Kudelski and J. L. Weyher, J. Phys. Chem. C, 2016, 120, 1841-1846.

7 V. Moraes, H. Riedl, R. Rachbauer, S. Kolozsvári, M. Ikeda, L. Prochaska, S. Paschen and P. H. Mayrhofer, J. Appl. Phys., 2016, 119, 225304.

8 Q. K. Qian, B. K. Li, M. Y. Hua, Z. F. Zhang, F. F. Lan, Y. K. Xu, R. Y. Yan and K. J. Chen, Sci. Rep., 2016, 6, 27676.

9 M. Conroy, V. Z. Zubialevich, H. Li, N. Petkov, S. O’Donoghue, J. D. Holmes and P. J. Parbrook, ACS Nano, 2016, 10, 1988-1994.

10 J. Lähnemann, M. Den Hertog, P. Hille, M. D. L. Mata, T. Fournier, J. Schörmann, J. Arbiol, M. Eickhoff and E. Monroy, Nano Lett., 2016, 16, 3260-3267.

11 C. Zervos, A. Adikimenakis, P. Beleniotis, A. Kostopoulos, M. Kayambaki, K. Tsagaraki, G. Konstantinidis and A. Georgakilas, Appl. Phys. Lett., 2016, 108, 142102.

12 A. Haider, S. Kizir, C. Ozgit-Akgun, E. Goldenberg, S. A. Leghari, A. K. Okyay and N. Biyikli, J. Mater. Chem. C, 2015, 3, 9620-9630.

13 J. Ju, B. Sun, G. Haunschild, B. Loitsch, B. Stoib, M. S. Brandt, M. Stutzmann, Y. K. Koh and G. Koblmüller, AIP Adv., 2016, 6, 045216.

14 L. Monteagudo-Lerma, S. Valdueza-Felip, A. Núñez-Cascajero, A. Ruiz, M. González-Herráez, E. Monroy and F. B. Naranjo, J. Cryst. Growth, 2016, 434, 13-18.

15 A. T. M. G. Sarwar, F. Yang, B. D. Esser, T. F. Kent, D. W. McComb and R. C. Myers, J. Cryst. Growth, 2016, 443, 90-97.

16 H. J.-Y. Chen, D.-L. Yang, T.-W. Huang and I.-S. Yu, Nanoscale Res. Lett., 2016, 11, 241.

17 Q. Chen, C. Yan and Y. Qu, Mater. Res. Express, 2017, 4, 035017.

18 T. Kente and S. D. Mhlanga, J. Cryst. Growth, 2016, 444, 55-72.
19 A. Haider, C. Ozgit-Akgun, F. Kayaci, A. K. Okyay, T. Uyar and N. Biyikli, APL Mater., 2014, 2, 096109.

20 C. Ozgit-Akgun, F. Kayaci, S. Vempati, A. Haider, A. Celebioglu, E. Goldenberg, S. Kizir, T. Uyar and N. Biyikli, J. Mater. Chem. C, 2015, 3, 5199-5206.

21 Y. T. Lin, T. W. Yeh, Y. Nakajima and P. D. Dapkus, Adv. Funct. Mater., 2014, 24, 3162-3171.

22 M. Müller, P. Veit, F. F. Krause, T. Schimpke, S. Metzner, F. Bertram, T. Mehrtens, K. Müller-Caspary, A. Avramescu, M. Strassburg, A. Rosenauer and J. Christen, Nano Lett., 2016, 16, 5340-5346.

23 M. Heilmann, A. M. Munshi, G. Sarau, M. Göbelt, C. Tessarek, V. T. Fauske, A. T. J. Van Helvoort, J. Yang, M. Latzel, B. Hoffmann, G. Conibeer, H. Weman and S. Christiansen, Nano Lett., 2016, 16, 3524-3532.

24 M. Reddeppa, B. G. Park, S. T. Lee, M. D. Kim, R. Kuchi and J. R. Jeong, Curr. Appl. Phys., 2016, 16, 886-889.

25 P. Varadhan, H.-C. Fu, D. Priante, J. R. D. Retamal, C. Zhao, M. Ebaid, T. K. Ng, I. Ajia, S. Mitra, I. S. Roqan, B. S. Ooi and J.-H. He, Nano Lett., 2017, 17, 1520-1528.

26 V. Kumaresan, L. Largeau, F. Oehler, H. Zhang, O. Mauguin, F. Glas, N. Gogneau, M. Tchernycheva and J.-C. Harmand, Nanotechnology, 2016, 27, 135602.

27 H. Liu, Q. Hua, R. Yu, Y. Yang, T. Zhang, Y. Zhang and C. Pan, Adv. Funct. Mater., 2016, 26, 5307-5314.

28 V. Kumaresan, L. Largeau, A. Madouri, F. Glas, H. Zhang, F. Oehler, A. Cavanna, A. Babichev, L. Travers, N. Gogneau, M. Tchernycheva and J. C. Harmand, Nano Lett., 2016, 16, 4895-4902.

29 M. Hetzl, F. Schuster, A. Winnerl, S. Weiszer and M. Stutzmann, Mater. Sci. Semicond. Process., 2016, 48, 65-78.

30 E. Li, B. Wu, S. Lv, Z. Cui, D. Ma and W. Shi, J. Alloys Compd., 2016, 681, 324-329.

31 P. Aseev, Z. Gačević, A. Torres-Pardo, J. M. González-Calbet and E. Calleja, Appl. Phys. Lett., 2016, 108, 253109.

32 F. Yu, D. Rümmler, J. Hartmann, L. Caccamo, T. Schimpke, M. Strassburg, A. E. Gad, A. Bakin, H. H. Wehmann, B. Witzigmann, H. S. Wasisto and A. Waag, Appl. Phys. Lett., 2016, 108, 213503.

33 G. Calabrese, P. Corfdir, G. Gao, C. Pfüller, A. Trampert, O. Brandt, L. Geelhaar and S. Fernández-Garrido, Appl. Phys. Lett., 2016, 108, 202101.

34 J. Zhang and C. Wang, J. Appl. Phys., 2016, 119, 145102.

35 O. Benner, C. Blumberg, K. Arzi, A. Poloczek, W. Prost and F. J. Tegude, Appl. Phys. Lett., 2016, 108, 082103.

36 N. P. Reddy, S. Naureen, S. Mokkapati, K. Vora, N. Shahid, F. Karouta, H. H. Tan and C. Jagadish, Nanotechnology, 2015, 27, 065304.

37 Y. Hu, Z. Hao, W. Lai, C. Geng, Y. Luo and Q. Yan, Nanotechnology, 2015, 26, 075302.

38 A. Adikimenakis, A. Lotsari, G. P. Dimitrakopulos, T. Kehagias, K. E. Aretouli, K. Tsagaraki, M. Androulidaki, P. Komninou and A. Georgakilas, J. Appl. Phys., 2015, 117, 244302.

39 P. R. Narangari, S. K. Karuturi, M. Lysevych, H. H. Tan and C. Jagadish, Nanotechnology, 2017, 28, 154001. 
40 I. H. Lee, H. S. Cho, K. B. Bae, A. Y. Polyakov, N. B. Smirnov, R. a. Zinovyev, J. H. Baek, T. H. Chung, I. V. Shchemerov, E. S. Kondratyev and S. J. Pearton, J. Appl. Phys., 2017, 121, 045108.

41 H. Hu, Z. Wu, W. Zhang, H. Li, R. Zhuo, D. Yan, J. Wang and P. Yan, J. Alloys Compd., 2015, 624, 241-246.

42 D. Lee, I. S. Shin, L. Jin, D. Kim, Y. Park and E. Yoon, J. Cryst. Growth, 2016, 444, 9-13.

43 A. T. Connie, S. Zhao, S. M. Sadaf, I. Shih, Z. Mi, X. Du, J. Lin and H. Jiang, Appl. Phys. Lett., 2015, 106, 213105.

44 E. Yanxiong, Z. Hao, J. Yu, C. Wu, R. Liu, L. Wang, B. Xiong, J. Wang, Y. Han, C. Sun and Y. Luo, Nanoscale Res. Lett., 2015, 10, 383.

45 H. M. Wu and Y. W. Peng, Ceram. Int., 2015, 41, 4847-4851.

46 S. Zhao, M. Djavid and Z. Mi, Nano Lett., 2015, 15, 7006-7009.

47 W. Zheng, F. Huang, R. Zheng and H. Wu, Adv. Mater., 2015, 27, 3921-3927.

48 A. T. M. Golam Sarwar, S. D. Carnevale, T. F. Kent, M. R. Laskar, B. J. May and R. C. Myers, J. Cryst. Growth, 2015, 428, 59-70.

49 B. K. Barick, C. Rodríguez-Fernández, A. Cantarero and S. Dhar, AIP Adv., 2015, 5, 057162.

50 J. Kamimura, P. Bogdanoff, M. Ramsteiner, L. Geelhaar and H. Riechert, Semicond. Sci. Technol., 2016, 31, 074001.

51 D. Bayerl and E. Kioupakis, Nano Lett., 2014, 14, 3709-3714.

52 Z. Mi and S. Zhao, Phys. Status Solidi B, 2015, 252, 1050-1062.

53 G. Liu, S. Zhao, R. D. E. Henderson, Z. Leonenko, E. AbdelRahman, Z. Mi and D. Ban, Nanoscale, 2016, 2097-2106.

54 V. Parameshwaran, X. Xu and B. Clemens, ACS Appl. Mater. Interfaces, 2016, 8, 21454-21464.

55 C. Bagavath, L. Nasi and J. Kumar, Mater. Sci. Semicond. Process., 2016, 49, 61-67.

56 K. Wang, T. Araki, T. Yamaguchi, Y. T. Chen, E. Yoon and Y. Nanishi, J. Cryst. Growth, 2015, 430, 93-97.

57 N. S. Karan, Y. Chen, Z. Liu and R. Beaulac, Chem. Mater., 2016, 28, 5601-5605.

58 K. K. Madapu, S. R. Polaki and S. Dhara, Phys. Chem. Chem. Phys., 2016, 18, 18584-18589.

59 K. S. Khashan and S. F. Abbas, Int. J. Mod. Phys. B, 2016, 30, 1650080.

60 F. I. Chowdhury, A. Alnuaimi, S. Alkis, B. Ortaç, S. Aktürk, M. Alevli, N. Dietz, A. K. Okyay and A. Nayfeh, Mater. Res. Express, 2016, 3, 056202.

61 H. Yang, J. Yin, W. Li, F. Gao, Y. Zhao, G. Wu, B. Zhang and G. Du, Vacuum, 2016, 128, 133-136.

62 K. K. Madapu, S. Dhara, S. Polaki, S. Amirthapandian and A. K. Tyagi, CrystEngComm, 2015, 17, 3139-3147.

63 H. Li, G. Zhao, H. Wei, L. Wang, Z. Chen and S. Yang, Nanoscale Res. Lett., 2016, 11, 270.

64 C. Tessarek, S. Fladischer, C. Dieker, G. Sarau, B. Hoffmann, M. Bashouti, M. Gobelt, M. Heilmann, M. Latzel, E. Butzen, S. Figge, A. Gust, K. Hoflich, T. Feichtner, M. Buchele, K. Schwarzburg, E. Spiecker and S. Christiansen, Nano Lett., 2016, 16, 3415-3425.
65 P. T. Terziyska, K. S. A. Butcher, P. Rafailov and D. Alexandrov, Appl. Surf. Sci., 2015, 353, 103-105.

66 H. Van Bui, F. Grillo and J. R. van Ommen, Chem. Commun., 2017, 53, 45-71.

67 N. Biyikli and A. Haider, Semicond. Sci. Technol., 2017, 32, 093002.

68 S. Altuntas, F. Buyukserin, A. Haider, B. Altinok, N. Biyikli and B. Aslim, Mater. Sci. Eng., C, 2016, 67, 590-598.

69 A. Haider, P. Deminskyi, T. M. Khan, H. Eren and N. Biyikli, J. Phys. Chem. C, 2016, 120, 26393-26401.

70 S. M. George, Chem. Rev., 2010, 110, 111-131.

71 C. Marichy, V. Salles, X. Jaurand, A. Etiemble, T. Douillard, J. Faugier-Tovar, F. Cauwet and A. Brioude, RSC Adv., 2017, 7, 20709-20715.

72 J. Jones, B. Beauclair, O. Olanipekun, S. Lightbourne, M. Zhang, B. Pollok, A. Pilli and J. Kelber, J. Vac. Sci. Technol., A, 2017, 35, 01B139.

73 N. Biyikli, C. Ozgit-Akgun, H. Eren, A. Haider, T. Uyar, F. Kayaci, M. O. Guler, R. Garifullin, A. K. Okyay, G. M. Ulusoy and E. Goldenberg, Proc. SPIE 9553, Low-Dimensional Materials and Devices, 2015, 9553, 95530C.

74 A. Haider, H. Cansizoglu, M. F. Cansizoglu, T. Karabacak, A. K. Okyay and N. Biyikli, J. Vac. Sci. Technol., A, 2015, 33, 01 A110.

75 F. Kayaci, S. Vempati, C. Ozgit-Akgun, I. Donmez, N. Biyikli and T. Uyar, Nanoscale, 2014, 6, 5735-5745.

76 H. Robatjazi, S. M. Bahauddin, L. H. Macfarlan, S. Fu and I. Thomann, Chem. Mater., 2016, 28, 4546-4553.

77 A. Y. Polyakov, A. V. Markov, M. V. Mezhennyi, A. V. Govorkov, V. F. Pavlov, N. B. Smirnov, A. A. Donskov, L. I. D'Yakonov, Y. P. Kozlova, S. S. Malakhov, T. G. Yugova, V. I. Osinsky, G. G. Gorokh, N. N. Lyahova, V. B. Mityukhlyaev and S. J. Pearton, Appl. Phys. Lett., 2009, 94, 022114.

78 M. Alevli, A. Haider, S. Kizir, S. A. Leghari and N. Biyikli, J. Vac. Sci. Technol., A, 2016, 34, 01A137.

79 S. Banerjee, A. A. I. Aarnink, R. van de Kruijs, A. Y. Kovalgin and J. Schmitz, Phys. Status Solidi, 2015, 12, 1036-1042.

80 A. Haider, C. Ozgit-Akgun, E. Goldenberg, A. K. Okyay and N. Biyikli, J. Am. Ceram. Soc., 2014, 97, 4052-4059.

81 A. Haider, S. Kizir and N. Biyikli, AIP Adv., 2016, 6, 045203. 82 A. Haider, S. Kizir, C. Ozgit-Akgun, A. K. Okyay and N. Biyikli, J. Vac. Sci. Technol., A, 2016, 34, 01A123.

83 M. Alevli, N. Gungor, A. Haider, S. Kizir, S. A. Leghari and N. Biyikli, J. Vac. Sci. Technol., A, 2016, 34, 01A125.

84 C. Ozgit-Akgun, E. Goldenberg, A. K. Okyay and N. Biyikli, J. Mater. Chem. C, 2014, 2, 2123-2136.

85 P. Motamedi and K. Cadien, J. Cryst. Growth, 2015, 421, 45-52. 86 H. Altuntas, T. Bayrak, S. Kizir, A. Haider and N. Biyikli, Semicond. Sci. Technol., 2016, 31, 075003.

87 M. Broas, P. Sippola, T. Sajavaara, V. Vuorinen, A. Pyymaki Perros, H. Lipsanen and M. Paulasto-Kröckel, J. Vac. Sci. Technol., A, 2016, 34, 041506.

88 P. Motamedi, N. Dalili and K. C. Cadien, J. Mater. Chem. C, 2015, 3, 7428-7436.

89 N. Nepal, R. Goswami, S. B. Qadri, N. A. Mahadik, F. J. Kub and C. R. Eddy, Scr. Mater., 2014, 93, 44-47.

90 N. Nepal, V. R. Anderson, J. K. Hite and C. R. Eddy, Thin Solid Films, 2015, 589, 47-51. 
91 H.-Y. Shih, M.-C. Lin, L.-Y. Chen and M.-J. Chen, Nanotechnology, 2015, 26, 014002.

92 J. K. Sprenger, A. S. Cavanagh, H. Sun, K. J. Wahl, A. Roshko and S. M. George, Chem. Mater., 2016, 28, 5282-5294.

93 S. Kizir, A. Haider and N. Biyikli, J. Vac. Sci. Technol., A, 2016, 34, 041511.

94 C. Gatzert, A. W. Blakers, P. N. K. Deenapanray, D. Macdonald and F. D. Auret, J. Vac. Sci. Technol., A, 2006, 24, 1857.
95 L. Qin, C. Xue, Y. Duan and L. Shi, Phys. B, 2009, 404, 190-193.

96 G. Santana-rodríguez, A. Mejía-montero, B. M. Monroypeláez, M. L. López, Y. L. Casallas-Moreno, M. RamírezLópez, G. Contreras-Puente and O. de Melo-Pereira, Mater. Sci. Appl., 2014, 5, 267-270.

97 H. C. M. Knoops, E. Langereis, M. C. M. van de Sanden and W. M. M. Kessels, J. Electrochem. Soc., 2010, 157, G241-249. 